\title{
The Biosocial Burden of HIV and Malaria Co-infection Among Pregnant Mothers
}

\author{
Adeoti Olatunde ${ }^{1,2, *}$, Adedoja Sulaimon ${ }^{1}$ \\ ${ }^{1}$ Department of Science Laboratory Technology, Faculty of Science, The Oke-Ogun Polytechnic, Saki, Nigeria \\ ${ }^{2}$ Cellular Parasitology Programme, Department of Zoology, Faculty of Science, University of Ibadan, Ibadan, Nigeria
}

Email address:

txy23m@yahoo.com (A. Olatunde)

${ }^{*}$ Corresponding author

\section{To cite this article:}

Adeoti Olatunde, Adedoja Sulaimon. The Biosocial Burden of HIV and Malaria Co-infection Among Pregnant Mothers. International Journal of Biomedical Materials Research. Vol. 5, No. 4, 2017, pp. 50-54. doi: 10.11648/j.ijbmr.20170504.11

Received: October 24, 2016; Accepted: November 8, 2016; Published: August 1, 2017

\begin{abstract}
Malaria and HIV/AIDS; exacerbated by poverty affects the poorest segments of the population by making them more vulnerable to infections due to lack of access to basic socio-economic needs. This study aimed at investigating the relationship between biosocial indices in relation to co-infection of HIV and malaria among participants. One hundred and forty-nine respondents were interviewed and administered with well-structured questionnaires. After informed consent, their venipunture blood samples were subjected to HIV and Malaria parasite screening by using standard protocols. All data obtained were transcribed and subjected to appropriate statistical analysis. Of the (149) mothers recruited, 32.9\% (49/149) were primigravidae while $27.5 \%$ (41/149) had more than one previous pregnancy (secungravidae). Respondents with Primary education were 53(35\%), 9(19.5\%) Secondary while 3(26.2\%) had no formal education. Fractions of $12.8 \%$ were government employees, $29.5 \%$ were self-employed, $2 \%$ were un-employed while $49.0 \%$ were of other categories. The household size of the respondents ranged from $78.2 \%$ with less than 5 members and $21.3 \%$ with more than 5 household members. Majority were of no salaried income status whereas the lowest percentage of $2.9 \%$ belongs to high income status. There was no statistically significant relationship between socioeconomic indices and prevalence of both HIV and malaria in pregnancy.
\end{abstract}

Keywords: Bio-Socio-Demographic, Multigravidae, Socio-Economic Status, Secundigravidae, Primigravidae, Parasitemia, Co-Infection

\section{Introduction}

According to the world malaria report of 2010 more than 225 million cases of malaria and an estimated 781, 000 deaths occurred in 2009 [23]. Most malaria deaths occurred among African children where a child dies every 45 seconds as a result of malaria [24] preventable cause. In the year 2012, malaria caused more than 627, 000 deaths, mostly among children [25]. Nigeria accounts for a quarter of all malaria cases in the 45 malaria-endemic countries in Africa, [23] where $11 \%$ of maternal mortality are as a result of malaria [10] infection, ranging from $19.7 \%$ to $72.0 \%$ [19, 3 , $13,22]$. The persistently high maternal mortality in Africa, Nigeria inclusive, may be associated with increasing numbers of HIV-associated death [21]. HIV was among the major causes of death among women in the reproductive age [20].
The epidemiology of HIV infection had changed and clinical evolution turned a fatal disease to a treatable chronic infection with an improved quality of life and a reduction of morbidity and mortality [21]. In 2010, it was estimated that people living with HIV infection were 34 million, 2.7 million people became newly infected in the same year and HIV related deaths were 1.8 million, including 250000 children [23]. However, there is a critical overlap between HIV and malaria two infections which posed a great threat for public health $[1,25]$. Both diseases are concentrated in tropical and sub-tropical regions of the world, particularly in sub-Saharan Africa. Also, socio-economically, Malaria and HIV/AIDS are worsened by poverty which increases the vulnerability of the poorest segments of a population. 


\section{Materials and Methods}

Saki is a rapidly growing peri-urban border town of over 187,000 inhabitants, located some one hundred and sixty-five kilometers from Ibadan, the Oyo state capital. The town has three secondary Health Care centers with more than thirty other primary and private health clinics. Notably, the HIV sero-prevalence of the town made it source of focus for health intervention programmes. The poor health seeking behaviour has greatly affected pregnant women seeking antenatal services. Seven Hospitals were selected based on the pilot study that suggested the selected hospitals as the seven best clinical services. Using stratified random selection, one hundred and forty-nine respondents were interviewed, taperecorded and administered with well-structured questionnaires. In order to complement this non-medical data collection, informed consent was sought from all the respondents before venipunture blood samples were collected which were later subjected to HIV and Malaria parasite screening by using the standard national protocol for serial HIV screening. The questionnaire was structured to obtain demographic, socio-economic status, bio-social information section. Both medical and the non-medical data obtained were transcribed and subjected to appropriate statistical analysis. Infection status was obtained through ANOVA and test of significance (Chi-square) method was used to relate infectious status and bio-socio parameters.

\section{Results}

Respondents who had primary education accounted for 53(35\%), whereas 9(19.5\%) had secondary and 3(26.2\%) did not attend any formal school (Figure 2). It was observed that among the respondents, 49 were primigravidae, $41(27.5 \%)$ and 59(39.6\%) were secungravidae and multigravidae respectively. The household size of less than 5 members was $78.2 \%$ and $21.3 \%$ had more than 5 members (Figure 5). The average number of respondents who earn more than twenty thousand naira ( $>\mathrm{N} 20,000$ per month was $2.9 \%$ (Figure 1 ). However, $12.8 \%$ of the respondents were governments' employees while 29.5\% were self-employed (Figure 4). Among all the respondents screened 45 had neither HIV nor malaria infection (Figure 3).

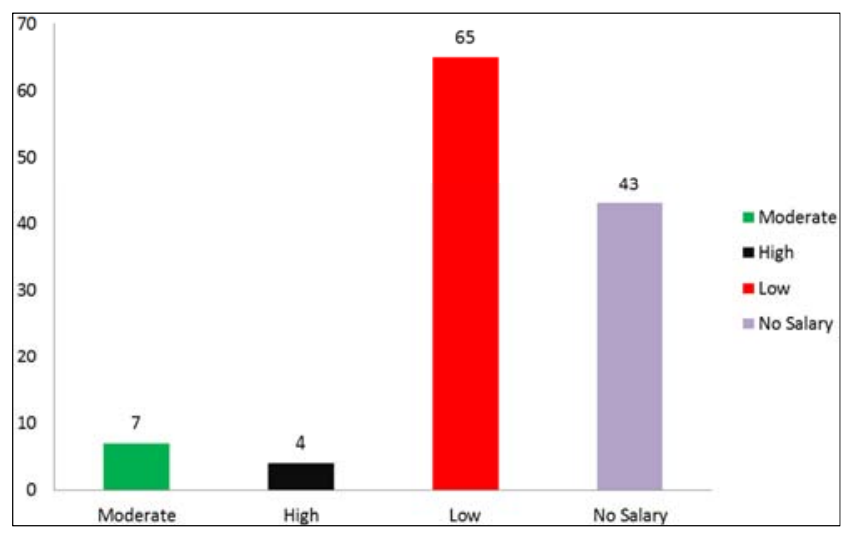

Figure 1. Monthly Income status of respondents.

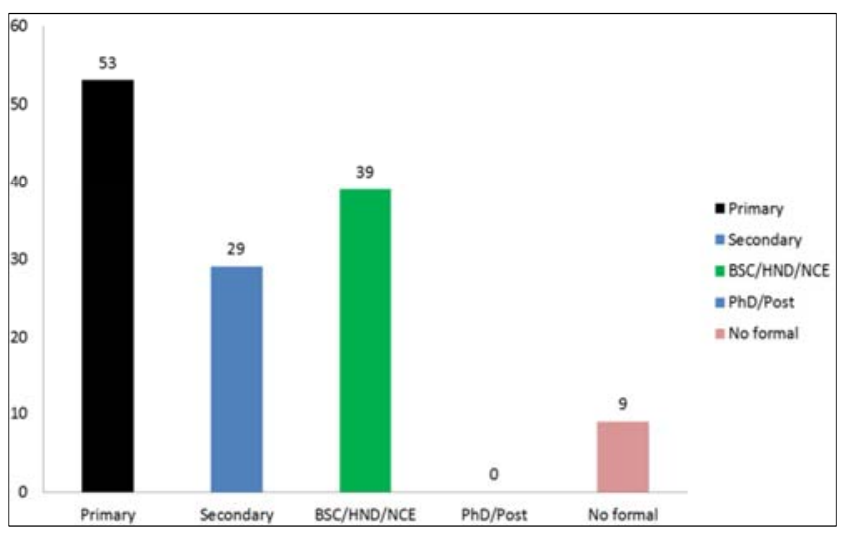

Figure 2. Highest literacy level of respondents.

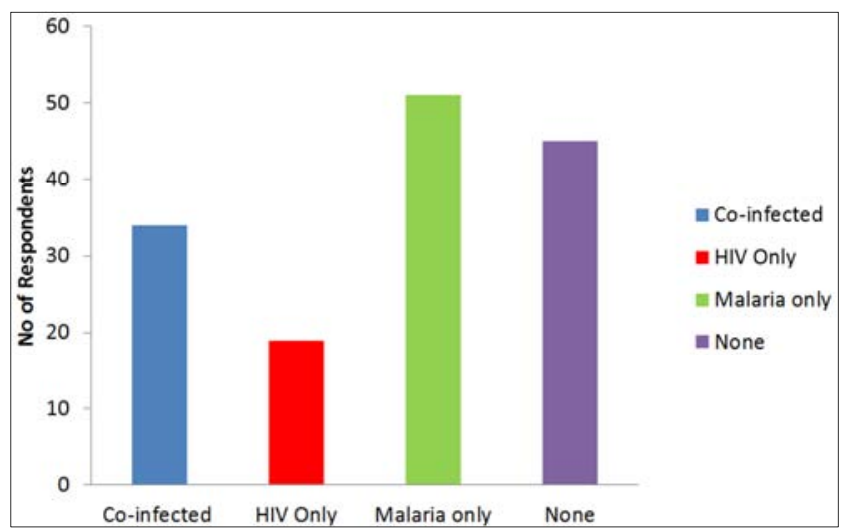

Figure 3. Infection categories of respondents.

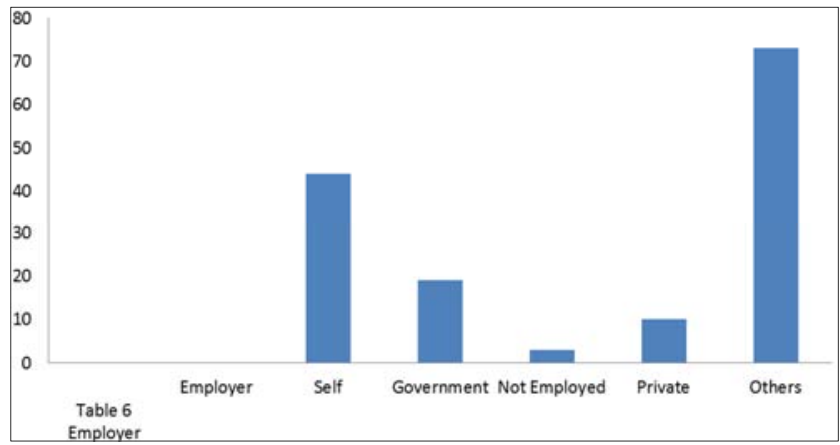

Figure 4. Category of Employers of respondents

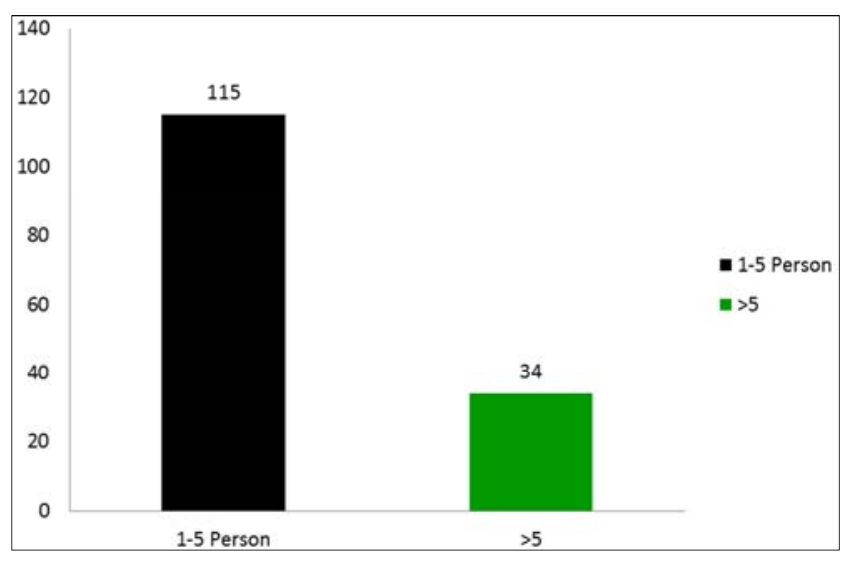

Figure 5. Household Size of respondents. 
Table 1. Prevalence of P. falciparum among the participating pregnant women in relation to age group.

\begin{tabular}{lllll}
\hline \multicolumn{2}{l}{ Malaria Status } & & & $\chi^{\mathbf{2}=5.351}$ \\
\hline Age Group & Negative (\%) & Positive (\%) & Total (\%) & p-values \\
\hline $15-19$ & $2(3.3)$ & $0(0.0)$ & $2(1.4)$ & \\
$20-24$ & $15(24.6)$ & $31(36.9)$ & $46(31.7)$ & \\
$25-29$ & $26(42.6)$ & $28(33.3)$ & $54(37.2)$ & 0.253 \\
$30-34$ & $13(21.3)$ & $17(20.2)$ & $30(20.7)$ & \\
$35-39$ & $5(8.2)$ & $8(9.5)$ & $13(9.0)$ & \\
Total & $61(100.0)$ & $82(100.0)$ & $145(100.0)$ & \\
\hline
\end{tabular}

$\chi^{2}=5.351, \mathrm{p}=0.253$, Not significant associations

Table 2. Prevalence of HIV among the participating pregnant women in relation to age group.

\begin{tabular}{lllll}
\hline HIV Status & & & & $\chi^{2}=\mathbf{2 . 4 6 8}$ \\
\hline Age group & Negative (\%) & Positive (\%) & Total (\%) & p-values \\
\hline $15-19$ & $1(1.1)$ & $1(1.9)$ & $2(1.4)$ & \\
$20-24$ & $28(30.4)$ & $18(34.0)$ & $46(31.7)$ & \\
$25-29$ & $39(42.4)$ & $15(28.3)$ & $54(37.2)$ & 0.330 \\
$30-34$ & $15(16.3)$ & $15(28.3)$ & $30(20.7)$ & \\
Total & $92(100.0)$ & $53(100.0)$ & $145(100.0)$ & \\
\hline
\end{tabular}

$\chi^{2}=4.607, p=0.330$, not significant associations

Table 3. Prevalence of P. falciparum malaria and HIV status in relation to participants'educational status.

\begin{tabular}{|c|c|c|c|c|}
\hline \multicolumn{5}{|l|}{ Infection status } \\
\hline \multirow[t]{2}{*}{ Literacy level } & \multicolumn{2}{|c|}{ Malaria status (\%) } & \multicolumn{2}{|c|}{ HIV status (\%) } \\
\hline & Negative & positive & negative & positive \\
\hline First school & $32(38.6)$ & $21(35.0)$ & $32(35.2)$ & $21(40.4)$ \\
\hline SSCE & $19(22.9)$ & $10(16.7)$ & $18(19.8)$ & $11(21.2)$ \\
\hline $\mathrm{BSc} / \mathrm{HND} / \mathrm{NCE}$ & $22(26.5)$ & $17(28.3)$ & $29(31.9)$ & $10(19.2)$ \\
\hline $\mathrm{PhD} /$ Post & $0(0.0)$ & $0(0.0)$ & $0(0.0)$ & $0(0.0)$ \\
\hline No formal & $10(12.0)$ & $12(20.0)$ & $12(13.2)$ & $10(19.2)$ \\
\hline Total & $83(100.0)$ & $60(100.0)$ & $91(100.0)$ & $52(100.0$ \\
\hline
\end{tabular}

Malaria: $\chi^{2}=2.468, p=0.650$; HIV: $\chi^{2}=6.099, p=0.192$. Not significant associations

Table 4. Prevalence of P. falciparum malaria and HIV status in relation to participants' employer.

\begin{tabular}{|c|c|c|c|c|}
\hline \multicolumn{5}{|l|}{ Infection status } \\
\hline \multirow[t]{2}{*}{ Employer } & \multicolumn{2}{|c|}{ Malaria status (\%) } & \multicolumn{2}{|c|}{ HIV status (\%) } \\
\hline & Negative & positive & negative & positive \\
\hline Self & $22(35.5)$ & $22(25.9)$ & $27(28.7)$ & $17(32.1)$ \\
\hline Govt & $9(14.5)$ & $10(11.8)$ & $16(17.0)$ & $3(5.7)$ \\
\hline Others & $4(6.5)$ & $6(7.1)$ & $7(74)$ & $3(5.7)$ \\
\hline Not employed & $27(33.5)$ & $47(55.3)$ & $44(46.8)$ & $30(56.6)$ \\
\hline Total & $62(100.0)$ & $55(100.0)$ & $94(100.0)$ & $53(100.0)$ \\
\hline
\end{tabular}

Malaria: $\chi^{2}=4.421 ; \mathrm{p}=0.352$, HIV: $\chi^{2}=6.546, \mathrm{p}=0.162$, Not significant associations

Table 5. Prevalence of P. falciparum malaria and HIV status in relation to participants' household size.

\begin{tabular}{lllll}
\hline Infection status & & & & \\
\hline Household size & \multicolumn{2}{l}{ Malaria status (\%) } & \multicolumn{2}{l}{ HIV status (\%) } \\
\hline & Negative & positive & negative & positive \\
\hline $1-5$ & $46(76.7)$ & $69(84.1)$ & $78(83.9)$ & $37(75.5)$ \\
$>5$ & $14(23.3)$ & $13(15.9)$ & $15(16.1)$ & $12(24.5)$ \\
Total & $60(100.0)$ & $82(100.0)$ & $93(100.0)$ & $49(100.0$ \\
\hline
\end{tabular}

Malaria: $\chi^{2}=1.137 ; \mathrm{p}=0.286$, HIV: $\chi^{2}=0, \mathrm{p}=0.415$. Not significant associations
Table 6. Prevalence of P. falciparum malaria and HIV status in relation to income status.

\begin{tabular}{|c|c|c|c|c|}
\hline \multicolumn{5}{|c|}{ Infection status } \\
\hline \multirow[t]{2}{*}{ Income } & \multicolumn{2}{|c|}{ Malaria status (\%) } & \multicolumn{2}{|c|}{ HIV status (\%) } \\
\hline & Negative & Positive & negative & positive \\
\hline Moderate & $2(3.6)$ & $5(7.8)$ & $5(5.7)$ & $2(6.7)$ \\
\hline High & $2(3.6)$ & $2(3.1)$ & $2(2.3)$ & $2(6.5)$ \\
\hline Low & $29(52.7)$ & $36(56.3)$ & $51(58.0)$ & $14(45.2)$ \\
\hline No income & $22(40.0)$ & $21(32.8)$ & $30(41.9)$ & $13(41.9)$ \\
\hline Total & $55(100.0)$ & $64(100.0)$ & $88(100.0)$ & $31(100.0)$ \\
\hline
\end{tabular}

Malaria: $\chi^{2}=2.302 ; p=0.512$, HIV: $\chi^{2}=6.546 ; p=0.162$. Not significant associations

\section{Discussion}

This study was in conformity with the study of [25] which documented general characteristics of pregnant mothers and related some selected characteristics with the prevalence of malaria during pregnancy. The present study showed that there was no statistically significant relationship between socioeconomic indices and transmission (prevalence) of coinfection of HIV and malaria in pregnancy. However, there was a significant association between mono- HIV and respondents' socio-economic status [8].

The prevalence rate of $55.3 \%$ and $56.6 \%$ of malaria and HIV respectively among unemployed women which was similar to several studies which evaluated the relationship between socioeconomic status by assessing the economic taste of respondents who were infected by both HIV and malaria $[9,4]$. The observed prevalence of Malaria and HIV infection among women with fewer household (1-5 members) could not be substantiated from the literature although there were evidence that Wealth Index (calculated by Income divided by the number of household) increases with fewer household [8].

It is expected that high prevalence of malaria and HIV should be observed among pregnant women who were from higher household (low economic well-being). Similarly, the result was in consonance with the report from African country which established a direct relationship between economic well-being, the risk of HIV infection. In other words; the wealthier a man is, the more likely he engages in multiple sex partners thereby increasing his chances of HIV infection [12].

This study it was observed that among low income and noincome earners in the sampled population harboured the highest prevalence of falciparum malaria. Although, this supported the long standing reports establishing that malaria is not only a disease of poverty but a cause of poverty [11, 24]. The prevalence of $P$. falciparum infection rate observed in this study may be due to several factors characteristic of the study area such as lack of proper sanitation and peak of malaria transmission. This study further supported malaria as disease of public health importance and this could be complicated by lack of quality antenatal services, poor service delivery; all of which are burden of malaria infection $[18,25]$. 
The HIV sero-prevalence was also high among the low and no-income earners (Table 6), giving credence to the belief that women in rural areas are more susceptible to HIV infection because they often have limited employment choices, making them prey with far less financially secure than men, with earnings of $18 \%$ of the typical salary of a man [4]. The HIV prevalence was highest among women with primary education, and moderately high among women with secondary education (Table 3 ); this is similar to the result of the sentinel study conducted in 2010 in Nigeria [10] where the highest HIV prevalence was documented among women with primary and secondary education and the least was observed among those with Islamic educational background. However, there was no statistically significant relationship between gravidity, gestational age and infection status in consonance with earlier reports. [10], however established a strong association between gravidity and prevalence of malaria in pregnancy. Generally, in agreement with [5, 7], there was no difference in socio-economic and demographic factors for HIV and malaria [8]. However, in contrast to earlier works there was no significant association between age of respondents and the two infections investigated among pregnant mothers [6] indicating a slow acquisition of active immunity, thereby suggesting that older adults might have lost some degree of immunity to confront certain ailments. The pattern of malaria prevalence among rural and urban dwellers varies $[16,26]$ and the co-infection rate in urban Ibadan and Saki is expected to vary depending on several behavioral and socio economic factors [7].

\section{Conclusion}

There seem to be no-significant relationship between biosocial indices and the rate or prevalence of HIV and falciparum malaria infection among the respondents.

\section{References}

[1] Abu-Raddad, L. J., Patnaik, P., Kublin, J. G., 2006. Dual infection with HIV and malaria fuels the spread of both diseases in sub-Saharan Africa. Science 314:1603-1606.

[2] Achidi, E. A., Anchang-Kimbi, J. K., Nkegoum, B, Sverremark-EkstrÖm, E, and Troye-Blomberg, M. 2009. Diagnostic comparison of malaria infection in peripheral blood, placental blood and biopsies in Cameroonian pluirepotent women. Malaria Journal 8:126.

[3] Adefioye, O. A., Adeyeba, O. A., Hassan, W. O., and Oyeniran, O. A., 2007. Prevalence of malaria parasite infection among pregnant women in Osogbo, Southwest Nigeria.American and European Journal of Science Research 2: 43-45.

[4] Audet, C. M., Burlison, J., Moon, T. D., Sidat, M., Vergara, A. E., and Vermund, S. H., 2010. Sociocultural and Epidemological aspects of HIV/AIDS in Mosambique, International Health and Human Rights.

[5] Auvert, B., Buve, A., Lagarde, E, Kahindo, M, Chege, J, Rutenberg, N, Musonda, R, Laouru, M, Akam, E., Weiss, HA.
2001. Male circumcision and HIV infection in four cities in sub-Saharan Africa. AIDS Supplementation 4: S 31-41.

[6] Bigoga, J. D., Manga, L., Titanji, V. P., Coetzee, M., Leke, R. G., 2007. Malaria vectors and transmission dynamics in Coastal south-Western Cameroon. Malaria Journal 6:5-9.

[7] Buve, A., Carael, M., Hayes, R. J., 2001. The multicentre study on factors determining the differential spread of HIV in four African cities 36: summary and conclusions. AIDS 15. 4:S127-S131.

[8] Cuadros, D. F., Branscum, A. J., Garcia-Ramos, 2011. No evidence of association between HIV-1 and malaria in populations with low HIV-1 prevalence PLoS/ONE Open Access.

[9] Dibua, U. M. E., Badger-Emeka, L., Ugonabo, J. A. 2013. HIV and malaria co-infection: their combined effects on pregnancy outcomes in Anambra State, south-East Nigeria. International Journal of Medicine and Medical Sciences. 5.10: 438-449.

[10] Federal Ministry of Health, 2011. Global AIDS response country report, by National Agency for the Control of AIDS cited at www.unaids.org/endataanalysis/know.

[11] Gallup, J. L., Sachs, J. D., 2001. The Economic burden of malaria. American Journal Tropical Medicine Hygiene, 64:8596.

[12] Hargreaves, J. R., Morison, L. A., Chege, J., Rutenburg, N., Kahindo, M., Weiss, H. A., Hayes, R., 2002.Socioeconomic status and risk of HIV infection in an urban population in Kenya. Tropical Medicine and International Health 7. 9: 793802 .

[13] Kagu, M. B., Kawuwa, M. B., Gadzama, G. B., 2007. Anaemia in pregnancy a cross-sectional study of pregnant women in Osogbo, Southwest, Nigeria, American-Eurasian Journal of Science Research, 2:43-45.

[14] Msisha, W. M., Kapiga, S. H., Earls, F., and Subramanian, S., 2008. Socioeconomic status and HIV seroprevalence in Tanzanis; a counter intuitive relationship, International Journal of Epidemiology. 10:34-39.

[15] Namusoke, F., Rasti, N., Kironde, F., Wahlgren, M., Mirambe, F., 2010. Malaria burden in pregnancy at mulago national referral Hospital in Kampala Uganda. Malaria Research and Treatment. 13857: 1-10.

[16] Ogbodo, S. O., Nwagha, U. I., Okaka, O. N. C., Ogenyi, S. C., Okoko, R. O., Nwagha, T. U., 2009. Malaria parasitemia among pregnant women in rural community of eastern Nigeria: need for combined measures. NigerianJournal of Physiological Sciences 24. 2:95-100.

[17] Okonko, I. O., Adejuwon, O. A., and Okerentugba, P. O., Innocent-Adiele, H. C., 2012. Circulating Plasmodium falciparum and HIV-1/2 as co-infection among blood donors in Ibadan, south-Western Nigeria. Nature and Science 10. 9: 42-47.

[18] Okonofua, K., Omo-Aghoja, L., Bello, Z., Osughe, M., Aghonlahor, K. 2010.Self-reporting of induced abortion by women attending prenatal clinics in Urban Nigeria. International Journal of Gynecology and Obstetrics: 111 2:122-125.

[19] Okwa, O. O. 2003. The status of malaria among pregnant women: a study in Lagos, Nigeria. African Journal of Reproductive Health. 17:23-27. 
[20] Onakewhor, J. U., Olagbuji B. N., Ande A. B., Ezenochie M. C., Olokor O. E., and Okonofua F. E., 2011. HIV/AIDS related maternal mortality in Benin City, Nigeria Ghana. Medical Journal 46:2-8.

[21] Prakash, D., Fesel, C., Jain, R. M., Cazenave, G. C., Mishra, Pied, S. 2006. Clusters of cytokines determine malaria severity in Plasmodium falciparum-infected patients in endemic areas of central India. Journal of Infectious Diseases. 194: 198-207.

[22] Uneke, C. J., 2007. Assessment of malaria in pregnancy using Rapid Diagnostic Tests and its association with Plasmodium falciparum parasitaemia. AIDS, 13:1145-1146.

[23] World Health Organization2011. Malaria and HIV interactions and their implications for public health policy http://www.who.int/malaria/malaria/malariaHIV/malaria HIV interactions report. PDF.
[24] World Health Organization 2004. Malaria and HIV interactions and their implication for public health Policy: report of a WHO technical consultation, Geneva, Switzerland, 23-25.

[25] World Health Organization, 2012. Roll Back Malaria partnership, WHO Focus in Nigeria. Progress and Impact series community report.4:58.

[26] Yahaya, O., Miachi, O. E., Umar, I. O., and Uwaokhonye, E. 2009.Malaria parasitemia among pregnant women with multiple child birth attending ante-natal clinics in parts of Idah and Igalamela/Odolu local government areas of Kogi State, Nigeria. International Journal of Medicine and Medical Sciences. 1.11: 527-529. 